\title{
Analyses of Crime Patterns in NIBRS Data Based on a Novel Graph Theory Clustering Method: Virginia as a Case Study
}

\author{
Peixin Zhao, ${ }^{1}$ Marjorie Darrah, ${ }^{2}$ Jim Nolan, ${ }^{3}$ and Cun-Quan Zhang ${ }^{2}$ \\ ${ }^{1}$ School of Management, Shandong University, Jinan, Shandong, China \\ ${ }^{2}$ Department of Mathematics, West Virginia University, Morgantown, WV, USA \\ ${ }^{3}$ Department of Sociology and Anthropology, West Virginia University, Morgantown, WV, USA
}

Correspondence should be addressed to Peixin Zhao; pxzhao@126.com

Received 28 January 2014; Accepted 25 February 2014; Published 20 March 2014

Academic Editors: Y. Mao, X. Meng, and J. Zhou

Copyright (C) 2014 Peixin Zhao et al. This is an open access article distributed under the Creative Commons Attribution License, which permits unrestricted use, distribution, and reproduction in any medium, provided the original work is properly cited.

\begin{abstract}
This paper suggests a novel clustering method for analyzing the National Incident-Based Reporting System (NIBRS) data, which include the determination of correlation of different crime types, the development of a likelihood index for crimes to occur in a jurisdiction, and the clustering of jurisdictions based on crime type. The method was tested by using the 2005 assault data from 121 jurisdictions in Virginia as a test case. The analyses of these data show that some different crime types are correlated and some different crime parameters are correlated with different crime types. The analyses also show that certain jurisdictions within Virginia share certain crime patterns. This information assists with constructing a pattern for a specific crime type and can be used to determine whether a jurisdiction may be more likely to see this type of crime occur in their area.
\end{abstract}

\section{Introduction}

The National Incident-Based Reporting System (NIBRS) is a crime reporting program for local, state, and federal law enforcement agencies that provides a wealth of incident level data for use in analysis. It is part of the Uniform Crime Reporting (UCR) Program which is administered by the FBI. The UCR Program provides a nationwide view of crime based on data submitted through state programs or directly to the national UCR Program and has been operational for around 70 years. The NIBRS was implemented in the late 1970s to meet law enforcement need for the 21st century. This vast system houses information on offenses, victims, offenders, property, and persons arrested, as well as the incident itself. The data of NIBRS are well structured and readily available for researchers and law enforcement agencies to assist with understanding the intricate nature of crime.

Akiyama and Nolan [1] outlined the structure of the NIBRS data set and provided methods for understanding and analyzing the data. Dunn and Zelenock [2] also describe and test procedures to facilitate the use of this vast system. Building on these initial works, many authors continue to investigate how this storehouse of data can be turned into useful information for researchers and law enforcement agencies. Much of the work employs descriptive statistics applied in various sophisticated ways to extract information from the files. For example, Thompson et al. [3] apply descriptive statistics to examine intimate partner violence and make connections between this crime and other crimes that occurred in the same incident. They were able to show a link between intimidation and more serious violent crimes and extract information about the relationships between the victim and the offender from the NIRBS data that helps to better understand this type of crime. Snyder [4] used logistic regression techniques to predict the arrest of juvenile robbery offenders. More recently, Addington and Rennison [5] used logistic regression models along with the NIBRS and the National Crime Victimization Survey (NCVS) data for predicting rape cooccurrence to provide a critical initial look at rapes that occur with other crimes.

For criminologists the NIBRS data holds the answers to many long-standing questions about crime, criminal offending, and crime victimization. However, gaining access to some of these answers has remained difficult because of 
the size and complexity of the data. Effective techniques, such as data mining and clustering, for criminal justice data are of increasing importance to both the research and law enforcement communities [6]. In recent years, clustering categorical data has gained more importance because it is one of the fundamental methods in data mining [7]. Clustering crime data, as with other categorical data, is unsupervised learning that aims at partitioning a data set into groups of similar items. The goal is to create clusters of data objects where the within-cluster similarity is maximized and the between-cluster similarity is minimized. Over the years, many clustering algorithms have been developed and tested. Some clustering techniques have developed specifically for use with categorical data. Abdu [8] presented three new clustering algorithms that were applied to the clustering of the NIBRS data. Two of his approaches combine spectral analysis and clustering techniques that are scalable to large data sets such as the NIBRS.

Clustering categorical data poses a challenge not encountered in clustering numerical data because the attribute categories are not ordered and defining a metric with which to measure the distance between data objects in a data set becomes a challenge. Many of the algorithms that have emerged for clustering categorical data rely on the occurrence/cooccurrence frequencies of attribute values in the data set to determine clusters of similar data objects. The basic goal is to choose a set of attribute categories that provide a summary of the data objects in a cluster. There are a wide range of clustering algorithms for categorical data, including K-modes [9], STIRR [10], CACTUS [11], ROCK [12], COOLCAT [13], LIMBO [14], and CLICKS [15]. A good summary can be found in [8]. The clustering algorithm used in this research is a mathematically well-defined model implemented in a polynomial time algorithm that guarantees an optimal solution [16].

Due to the lack of well-defined mathematical models and optimization goals, most existing graph theory clustering approaches could not guarantee a proper clustering result in general cases. For example, agglomerative hierarchical clustering methods could not produce proper clusters with larger sizes, while divisive hierarchical methods could not produce clusters with smaller sizes, and clusters with large difference in their sizes and $\mathrm{k}$-core method may produce clusters with small edge-cuts, and so forth. Many papers and articles have mentioned these problems and frustration among users (e.g., see [17-19]). Even the most popular commercial software, SAS, is unable to produce proper outputs for some simple data.

The purpose of this paper is to present a novel multidimensional clustering method for the NIBRS data. We firstly outlines a new measure, called the likelihood index, that helps examine quantitatively how likely a crime is to occur in a particular jurisdiction. This measure compares a vector that describes a jurisdiction with a vector that represents a crime type. Then according to the defined distance between these two vectors, we can determine how closely the jurisdiction aligns with that crime type. The data used in this study were obtained from the 2005 NIBRS which is stored at the National Archive for Criminal Justice Data at the University
TABLE 1: NIBRS indexes used.

\begin{tabular}{|c|c|c|}
\hline Segment & Index & $\begin{array}{l}\text { Number of } \\
\text { subindexes }\end{array}$ \\
\hline \multirow{8}{*}{ Victim indexes } & Type of victim & 3 \\
\hline & Victim age & 3 \\
\hline & Victim sex & 2 \\
\hline & Victim race & 5 \\
\hline & Victim ethnicity & 3 \\
\hline & Victim residence status & 3 \\
\hline & $\begin{array}{l}\text { Aggravated assault/homicide } \\
\text { circumstances }\end{array}$ & 10 \\
\hline & Type of injury & 6 \\
\hline \multirow{3}{*}{ Offender indexes } & Offender age & 3 \\
\hline & Offender sex & 3 \\
\hline & Offender race & 5 \\
\hline \multirow{10}{*}{$\begin{array}{l}\text { Additional } \\
\text { indexes }\end{array}$} & Injury & 2 \\
\hline & Juvenile & 1 \\
\hline & Violent crime & 1 \\
\hline & Juvict & 1 \\
\hline & Multiple victims & 1 \\
\hline & Multiple offenders & 1 \\
\hline & Multiple offenders and victims & 1 \\
\hline & $\begin{array}{l}\text { Multiple offenders and one } \\
\text { victim }\end{array}$ & 1 \\
\hline & $\begin{array}{l}\text { One offender and multiple } \\
\text { victims }\end{array}$ & 1 \\
\hline & One offender and one victims & 1 \\
\hline
\end{tabular}

of Michigan. This work explores the following research questions. Do specific crimes exhibit certain quantifiable characteristics? Do different types of crimes share similar quantifiable characteristics? Do jurisdictions of a state cluster with respect to different crime types? What is the likelihood that if one type of crime is occurring in an area, other types of crime with similar quantifiable characteristic will also occur in that area?

The rest of the paper is organized as follows. In Section 2 we summarize the data unit of analysis and preparation. In Section 3 we introduce the methods to deal with the data matrix and take Virginia as a case study. Section 4 provides some additional results and Section 5 gives the conclusions of the research.

\section{Data Unit of Analysis and Preparation}

The data sets available in the NIBRS provide a wealth of incident level data about each reported crime. As for 2010, approximately 40 states contribute their data to the massive data set. The data and tools are made available by University of Michigan for use by law enforcement agencies and researchers. In order to devise a manageable set of data for preliminary testing of techniques and for preliminary data analysis, only the 2005 data on assaults were explored. From the 2005 assault data, 121 jurisdictions (counties or cities) in 
Virginia were selected for examination. These represent all jurisdictions within Virginia with populations greater than 10,000. There were 10,183 incidents reported in these 121 chosen jurisdictions.

For this study, 21 indexes from the NIBRS were chosen from the 246 available indexes. These 21 indexes were deemed important to provide the relevant characteristics of the victim(s), offender(s), and the circumstances of each incident. The selected particular indexes were listed in Table 1.

In order to facilitate the selected analysis techniques, the data was expanded from one column, with many possible entries, to multi columns that contained zero or one. For example, the Offender Segment index contains the sex of the offender and has the possible entries of male, female, or unknown. This index column was split into three individual columns where an entry in the three columns of $\left(\begin{array}{lll}1 & 0 & 0\end{array}\right)$ means female, $\left(\begin{array}{lll}0 & 1 & 0\end{array}\right)$ means male, and $\left(\begin{array}{lll}0 & 0 & 1\end{array}\right)$ means unknown. This turns the column for sex of the offender to three columns. All created columns were binary (0/1) columns that were used to help classify the characteristics of the incident. From the expansion of the original 21 indexes, 57 binary columns were created. This led to the creation of a $121 \times 57$ Crime Data Matrix, where each row $i$ represents the $i$ th jurisdiction and each column $j$ represents the $j$ th parameter related to the incident (e.g., offender sex, victim resident status) or a crime type (e.g., hate crime, drug dealing). The Crime Data Matrix construction is pictured below:

$$
\text { Crime Data Matrix }=\left[\begin{array}{ccc}
a_{1,1} & \ldots & a_{1,57} \\
\vdots & \ddots & \vdots \\
a_{121,1} & \ldots & a_{121,57}
\end{array}\right]
$$

where $a_{i, j}$ is the entry of the $j$ th crime index from the $i$ th jurisdiction.

Normalization of the rows of the matrix was completed by dividing each row entry by the population of the jurisdiction. This gave a per person rate for each crime parameter or each crime type. Normalization of the columns was completed by averaging the columns and subtracting the average from each entry in the column. Then each entry in the column was divided by the vector length of the column. Equation (2) shows these normalization step-by-step operations.

$$
\begin{gathered}
a_{i, j} \longleftarrow \frac{\text { number of occurances of crime parameter or crime type }}{\text { population of the jurisdiction }}, \\
a_{i, j} \longleftarrow a_{i, j}-g_{j} \text { where } g_{j} \text { is the average of the jth column, } \\
a_{i, j} \longleftarrow \frac{a_{i, j}}{n_{j}} \text { where } n_{j} \text { is the vector length of the } j \text { th column. }
\end{gathered}
$$

\section{Finding Patterns in the Data}

This section explains several different analyses that were performed on the data in the matrix described above in order to attempt to answer the research questions listed in Section 1. These analyses include comparing the columns of the matrix to determine the correlation of crime parameters to crime types and to determine the correlation of different crime types. Also there were two analyses performed comparing the row vectors to develop the likelihood index and to cluster the jurisdictions by crime types.

3.1. Correlation of Crime Parameters and Crime Types (Comparing the Column Vectors). The motivation for comparing the different crime parameters to crime types is to determine if there are some characteristics that can tell us about the likelihood of a crime type to occur in a certain jurisdiction. Each crime type may have factors that contribute to a specific crime appearing in a certain place. An overall increase in crime in an area may or may not correlate to an increase in any one particular type of crime, say hate crime, in that area. However, there may be individual parameters whose increase may indicate an increase in a particular type of crime. For example, if juvenile offenders are up in a certain area, this may indicate that hate crimes will also be up in that area. Also crime type vectors were compared against each other in a similar way. For example, crimes like juvenile gang were compared against hate crime to see if these crime types also have a correlation.

In order to determine the relationship between the $j$ th parameter ( $j$ th column of the Crime Data Matrix) and any other column (another parameter or another crime type), the correlation coefficient (cosine of the angle between the two column vectors over the norm of the vectors) was calculated. Each of the columns of the crime data matrix forms a vector in a 121-dimensional space and the vectors can be geometrically compared, with the correlation between two parameters represented by the cosine of the angle in this space. For example, the column for the juvenile offender could be compared against the column for hate crime or the column for hate crime can be compared to the column for gangrelated crime. These comparisons are made by calculating the angle between these two columns to determine if there is any relationship and how strong that relationship may be. This method can assist in determining whether two columns vary directly, inversely, or separately.

For this comparison of two column vectors, the variation in two vectors must be transformed to eliminate the effects of mean differences. Once the mean deviation is determined, then the correlation can be determined by the cosine of the angle between the vectors. As an example, let $j=$ $\left(j_{1}, j_{2}, \ldots, j_{121}\right)$ be the column for juvenile offender and let 


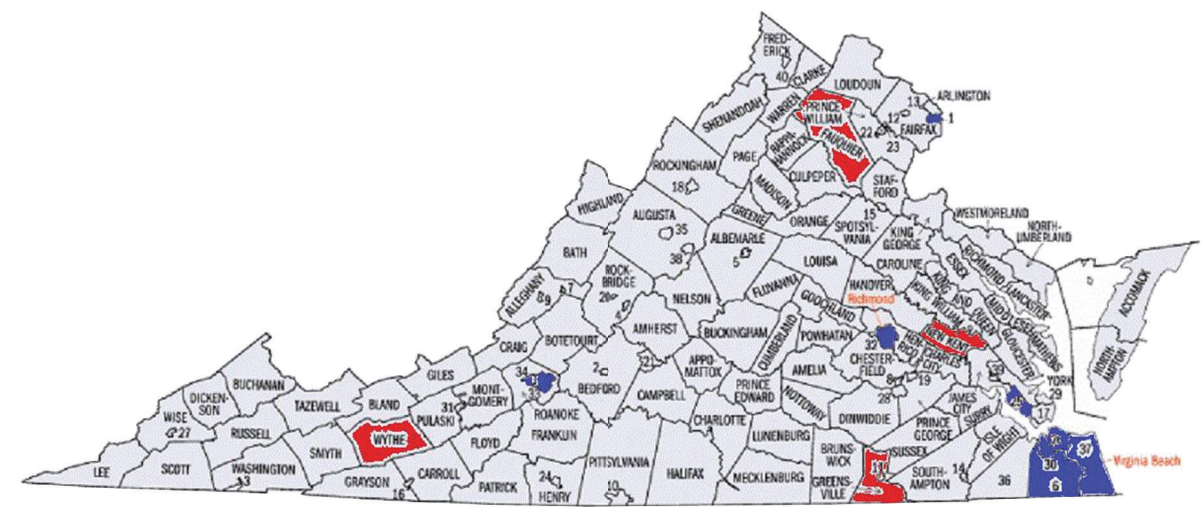

Independent cities

$\begin{array}{llll}\text { (1) Alexandria } & \text { (11) Emporia } & \text { (21) Lynchburg } & \text { (31) Radford } \\ \text { (2) Bedford } & \text { (12) Fairfax } & \text { (22) Manassas } & \text { (32) Richmond } \\ \text { (3) Bristol } & \text { (13) Falls Church } & \text { (23) Manassas Park } & \text { (33) Roanoke } \\ \text { (4) Buena Vista } & \text { (14) Franklin } & \text { (24) Martinsville } & \text { (34) Salem } \\ \text { (5) Charlottesville } & \text { (15) Fredericksburg } & \text { (25) Newport News } & \text { (35) Staunton } \\ \text { (6) Chesapeake } & \text { (16) Galax } & \text { (26) Norfolk } & \text { (36) Suffolk } \\ \text { (7) Clifton Forge } & \text { (17) Hampton } & \text { (27) Norton } & \text { (37) Virginia Beach } \\ \text { (8) Colonial Heights } & \text { (18) Harrisonburg } & \text { (28) Petersburg } & \text { (38) Waynesboro } \\ \text { (9) Covington } & \text { (19) Hopewell } & \text { (29) Poquoson } & \text { (39) Williamsburg } \\ \text { (10) Danville } & \text { (20) Lexington } & \text { (30) Portsmouth } & \text { (40) Winchester }\end{array}$

FIGURE 1: The clustering results of 121 counties in Virginia according to hate crime.

$h=\left(h_{1}, h_{2}, \ldots, h_{121}\right)$ be the column for the hate crime indicator. To find the correlation coefficient of this two columns calculate the following:

$$
\alpha_{j}=\cos \theta_{j}=\frac{\sum_{i} j_{i} h_{i}}{\|j\|\|h\|} .
$$

The sign of the answer is ignored, since either a strong positive relationship (close to 1 meaning that the two angles are in the same direction and close to one another) or a strong negative relationship (close to -1 meaning that the two angles are in opposite directions, but nearly opposite one another) indicates that the vectors appear to be related in some way.

In doing this comparison, with one vector fixed and comparing it to all other vectors and itself, we form a row vector of size 57. Consider the example that compares the hate crime vector with all other vectors. We construct another vector that we refer to as the Hate Crime Character Vector of size 57, which contains all the cosine $\theta_{j}$ (the correlation coefficient of the $j$ th parameter with respect to hate crime). A new vector is formed from all these correlation coefficients $\left(\alpha_{1}, \alpha_{2}, \ldots, \alpha_{57}\right)$, where each of the 57 parameters has a correlation coefficient vector associated with it. Now consider the corresponding components in the Hate Crime Character Vector. Table 2 tells us how hate crimes are related to aggravated assault crimes. Among those crimes, juvenile gang (0.4058) has higher correlation with hate crime, while the others, for example, argument (0.1325) and drug dealing $(0.0265)$ have relatively lower correlation.

Table 3 also shows similar evidence that for victim's age, the age group less than 18 is also more correlated to hate crime than the other two age groups. Many such comparisons can be observed using these correlation coefficient vectors.

3.2. Analyses of Jurisdictions (Comparing the Row Vectors). By using the correlation coefficients, a 57-dimensional vector, two data analyses can be performed, each of which indicates the likelihood of a particular crime for each jurisdiction. The first one is a numerical index, called the likelihood index assigned to each of the 112 jurisdictions. The second one is a clustering analysis of all jurisdictions. Jurisdictions with similar recorded crime patterns (adjusted corresponding to correlation coefficients) form clusters.

Let $\beta=\left\{\beta_{1}, \beta_{2}, \ldots, \beta_{121}\right\}$ be the likelihood index vector where $\beta_{i}$ is the likelihood index between jurisdiction $i$ and a particular crime (e.g., hate crime) or crime parameter (e.g., juvenile offender). For this comparison of two row vectors, the variation in two vectors must be transformed to eliminate the effects of mean differences. Once the mean deviation is determined, then the correlation can be determined by the cosine of the angle between the vectors. As an example, let $k=$ $\left(k_{1}, k_{2}, \ldots, k_{57}\right)$ be the row for the Norfolk jurisdiction and let $l=\left(l_{1}, l_{2}, \ldots, l_{57}\right)$ be the row for the hate crime indicator. To find the correlation coefficient of these two rows calculate the following:

$$
\beta_{i}=\cos \phi_{i}=\frac{\sum_{j} k_{j} l_{j}}{\|k\|\|l\|} .
$$

Table 4 gives the top 30 jurisdictions of Virginia with respect to the hate crime likelihood index and also provides the data on the clustering of the jurisdictions discussed in the next section. 
TABLE 2: Hate crime correlation coefficient vector values for other crimes.

\begin{tabular}{lc}
\hline Crime type & $\begin{array}{r}\text { Hate crime correlation } \\
\text { coefficient }\left(\alpha_{j}\right)\end{array}$ \\
\hline Argument & 0.1325 \\
Assault on law enforcement officers & 0.0371 \\
Drug dealing & 0.0265 \\
Gangland (organized crime & 0.1565 \\
involvement) & $\mathbf{0 . 4 0 5 8}$ \\
Juvenile gang & -0.0281 \\
Lovers' quarrel & -0.0375 \\
Other felony involved & 0.0961 \\
Other circumstances & 0.1356 \\
Unknown circumstance & \\
\hline
\end{tabular}

TABLE 3: Hate crime correlation coefficients for age of victim.

\begin{tabular}{lc}
\hline Age of victim & Hate crime correlation coefficient $\left(\alpha_{j}\right)$ \\
\hline Age $<18$ & $\mathbf{0 . 4 9 4 4}$ \\
$18 \leq$ Age $\leq 60$ & 0.0540 \\
Age $>60$ & 0.0474 \\
\hline
\end{tabular}

3.3. Using the Correlation Coefficients to Cluster the Jurisdictions. To begin the clustering, a weighted complete graph with 121 vertices is formed. The weight on each edge is the correlation coefficient between the jurisdictions. The novel graph theory clustering method we proposed in [20] is used to find all the dense (highly weighted) subgraphs of the complete graph. A distinguished feature of this method, nonbinary hierarchical tree, clearly highlights meaningful clusters which significantly reduces further manual efforts for cluster selections. The results of clustering the jurisdictions with respect to hate crimes are also displayed in Figure 1 and Table 4 .

It can be seen that of the top 30 jurisdictions with respect to hate crimes, 12 of the top 15 are in Cluster A and the others are in Cluster B. The remaining 91 jurisdictions also fall into Cluster B. The 12 higher hate crime rate counties (cities) are showed in Figure 1 (in red and blue).

\section{Additional Results}

Similar analyses where performed with respect to other crime types: drug-dealing, juvenile gang, and gangland (organized crime involvement). The results are summarized in Tables 510.

Table 6 summarizes the drug dealing vector comparison with the offender parameter vectors.

Tables 5 and 6 summarize the comparison of the drug dealing vector with other crime parameter vectors. Each of the other crime parameters related to the victim and the offender was compared to the drug dealing vector. A high value for this correlation coefficient implies that there is a correlation between this crime parameter and drug dealing. Again, the motivation for comparing the different crime parameters to crime types is an attempt to determine if there
TABLE 4: Likelihood index and clustering for hate crime.

\begin{tabular}{|c|c|c|c|}
\hline & Name & Cluster & $\begin{array}{c}\text { Hate crime } \\
\text { likelihood index }\end{array}$ \\
\hline 1 & NEWPORT NEWS & B & 0.867 \\
\hline 2 & NORFOLK & B & 0.837 \\
\hline 3 & CHESAPEAKE & B & 0.810 \\
\hline 4 & GREENSVILLE & B & 0.762 \\
\hline 5 & PORTSMOUTH & B & 0.759 \\
\hline 6 & RICHMOND & B & 0.716 \\
\hline 7 & WYTHE & B & 0.681 \\
\hline 8 & ALEXANDRIA & B & 0.678 \\
\hline 9 & BRISTOL & B & 0.667 \\
\hline 10 & NEW KENT & B & 0.618 \\
\hline 11 & FAUQUIER & B & 0.531 \\
\hline 12 & ROANOKE & A & 0.439 \\
\hline 13 & RICHMOND & A & 0.386 \\
\hline 14 & WILLIAMSBURG & A & 0.377 \\
\hline 15 & VIRGINIA BEACH & B & 0.318 \\
\hline 16 & CHARLOTTESVILLE & A & 0.312 \\
\hline 17 & PETERSBURG & A & 0.280 \\
\hline 18 & SPOTSYLVANIA & A & 0.226 \\
\hline 19 & HOPEWELL & $\mathrm{A}$ & 0.205 \\
\hline 20 & RUSSELL & A & 0.121 \\
\hline 21 & CLARKE & A & 0.121 \\
\hline 22 & WINCHESTER & A & 0.118 \\
\hline 23 & SUFFOLK & A & 0.111 \\
\hline 24 & MARTINSVILLE & $\mathrm{A}$ & 0.075 \\
\hline 25 & STAUNTON & A & 0.073 \\
\hline 26 & GALAX & A & 0.070 \\
\hline 27 & SHENANDOAH & A & 0.063 \\
\hline 28 & CAROLINE & A & 0.044 \\
\hline 29 & SURRY & A & -0.020 \\
\hline 30 & DANVILLE & A & -0.094 \\
\hline
\end{tabular}

are some characteristics that can tell us about the likelihood of a crime type to occur in a certain jurisdiction. For example, the correlation between the drug dealing vector and individual victim is 0.5789 , which is much higher than the correlation between drug dealing and victim type business $(0.1721)$ or victim type society/public (0.1729). This would seem to imply that for jurisdictions where the individual victim crimes are evident they may also have the likelihood for drug dealing related crimes. The tables show the correlation coefficient values: the correlation values in bold show a higher correlation with the drug dealing crime type than the other parameters in that category.

Table 7 summarizes the drug dealing vector comparison with the other crime types. The highest correlation is with argument.

Each of the other crime parameters related to the victim and the offender was compared to the gangland (organized 
TABLE 5: Drug dealing correlation with other crime parameters related to victim.

\begin{tabular}{lc}
\hline & Drug dealing correlation coefficient \\
\hline Type of victim & $\mathbf{0 . 5 7 8 9}$ \\
individual & 0.1721 \\
Business & 0.1729 \\
Society/public & \\
Age of victim & 0.2933 \\
Age $<18$ & 0.3872 \\
Age $\geq 60$ & $\mathbf{0 . 5 9 9 3}$ \\
18 $\leq$ age $<60$ & \\
Sex of victim & $\mathbf{0 . 5 7 7 4}$ \\
Male & 0.4989 \\
Female & \\
Race of victim & 0.3906 \\
White & $\mathbf{0 . 5 0 2 8}$ \\
Black & 0.0764 \\
Asia/Pacific Islander & 0.0003 \\
Unknown & 0.0393 \\
American Indian & \\
Ethnicity of victim & 0.0688 \\
Hispanic origin & $\mathbf{0 . 6 0 0 9}$ \\
Not of Hispanic origin & -0.0616 \\
Unknown & \\
Resident status of victim & 0.2631 \\
Nonresident & $\mathbf{0 . 5 7 4 0}$ \\
Resident & 0.1290 \\
Unknown & \\
\hline
\end{tabular}

TABLE 6: Drug dealing correlation with other crime parameters related to offender.

\begin{tabular}{lc}
\hline Offender age & \\
Age $<18$ & 0.3514 \\
Age $\geq 60$ & 0.3762 \\
$18 \leq$ age $<60$ & $\mathbf{0 . 5 6 7 8}$ \\
Offender sex & \\
Male & 0.5331 \\
Female & $\mathbf{0 . 5 6 8 5}$ \\
Unknown & 0.1972 \\
Offender race & \\
White & 0.3145 \\
Black & $\mathbf{0 . 5 1 3 3}$ \\
American Indian/Alaskan native & -0.0479 \\
Unknown & 0.1948 \\
Asian/Pacific Islander & 0.113 \\
\hline
\end{tabular}

crime involvement) vector. There were no significant relationships to report from this comparison.

Table 8 gives the top 30 jurisdictions of Virginia with respect to the drug dealing likelihood index and also shows how the jurisdictions are clustered. Given the 121 Virginia jurisdictions being considered, of the top 30 with respect
TABle 7: Drug dealing correlation with other crime types.

\begin{tabular}{lc}
\hline Other crime types & \\
\hline Argument & $\mathbf{0 . 4 8 5 4}$ \\
Assault on law enforcement officer(s) & 0.3117 \\
Gangland (organized crime involvement) & 0.3456 \\
Juvenile gang & 0.0706 \\
Lovers' quarrel & 0.2967 \\
Other felony involved & 0.2955 \\
Hate crime & 0.0265 \\
\hline
\end{tabular}

TABLE 8: Likelihood index and clustering for drug dealing.

\begin{tabular}{|c|c|c|c|}
\hline & Name & Cluster & $\begin{array}{c}\text { Drug dealing } \\
\text { likelihood index }\end{array}$ \\
\hline 1 & CHARLOTTESVILLE & B & 0.9094 \\
\hline 2 & NEWPORT NEWS & B & 0.9012 \\
\hline 3 & CHESAPEAKE & B & 0.8851 \\
\hline 4 & PETERSBURG & B & 0.8637 \\
\hline 5 & RICHMOND & B & 0.8365 \\
\hline 6 & PORTSMOUTH & $\mathrm{A}$ & 0.8281 \\
\hline 7 & HOPEWELL & A & 0.7917 \\
\hline 8 & ROANOKE & B & 0.791 \\
\hline 9 & SUFFOLK & B & 0.7839 \\
\hline 10 & NORFOLK & B & 0.7756 \\
\hline 11 & BRISTOL & B & 0.7365 \\
\hline 12 & DANVILLE & A & 0.707 \\
\hline 13 & GREENSVILLE & $\mathrm{A}$ & 0.7032 \\
\hline 14 & GALAX & A & 0.6881 \\
\hline 15 & CAROLINE & $\mathrm{A}$ & 0.6852 \\
\hline 16 & SUSSEX & A & 0.6396 \\
\hline 17 & WINCHESTER & A & 0.6327 \\
\hline 18 & FREDERICKSBURG & B & 0.6031 \\
\hline 19 & CLARKE & A & 0.6021 \\
\hline 20 & FRANKLIN & A & 0.5808 \\
\hline 21 & RICHMOND & A & 0.5667 \\
\hline 22 & LYNCHBURG & $\mathrm{A}$ & 0.5395 \\
\hline 23 & MECKLENBURG & $\mathrm{A}$ & 0.5185 \\
\hline 24 & RADFORD & A & 0.5133 \\
\hline 25 & GOOCHLAND & A & 0.5114 \\
\hline 26 & MANASSAS & A & 0.494 \\
\hline 27 & HENRY & B & 0.4844 \\
\hline 28 & NORTON & A & 0.4456 \\
\hline 29 & WISE & B & 0.4381 \\
\hline 30 & WILLIAMSBURG & A & 0.395 \\
\hline
\end{tabular}

to the likelihood index, twelve are clustered together. Only three others jurisdictions from Cluster B appear outside the top 30; these jurisdictions are Smyth (35), Tazewell (37), and Pittsylvania (50). Each of the other crime parameters related to the victim and the offender was compared to the 
TABLE 9: Likelihood index and clustering for gangland (organized crime involvement).

\begin{tabular}{|c|c|c|c|}
\hline & Name & Cluster & $\begin{array}{c}\text { Gangland } \\
\text { likelihood index }\end{array}$ \\
\hline 1 & NEWPORT NEWS & B & 0.9217 \\
\hline 2 & ROANOKE & B & 0.8786 \\
\hline 3 & CHESAPEAKE & B & 0.8713 \\
\hline 4 & PETERSBURG & B & 0.8421 \\
\hline 5 & NORFOLK & B & 0.8129 \\
\hline 6 & RICHMOND & B & 0.7953 \\
\hline 7 & LYNCHBURG & B & 0.6965 \\
\hline 8 & FREDERICKSBURG & B & 0.689 \\
\hline 9 & BRISTOL & B & 0.6787 \\
\hline 10 & ALEXANDRIA & B & 0.6569 \\
\hline 11 & NORTHAMPTON & B & 0.632 \\
\hline 12 & LOUDOUN & B & 0.4939 \\
\hline 13 & CHARLOTTESVILLE & A & 0.4152 \\
\hline 14 & STAFFORD & B & 0.3853 \\
\hline 15 & PORTSMOUTH & A & 0.3075 \\
\hline 16 & HOPEWELL & A & 0.2724 \\
\hline 17 & GALAX & A & 0.2121 \\
\hline 18 & CAROLINE & A & 0.1372 \\
\hline 19 & SUFFOLK & A & 0.1077 \\
\hline 20 & GREENSVILLE & $\mathrm{A}$ & 0.0817 \\
\hline 21 & CLARKE & $\mathrm{A}$ & 0.0689 \\
\hline 22 & DANVILLE & A & 0.0519 \\
\hline 23 & HENRY & A & 0.0518 \\
\hline 24 & RICHMOND & A & 0.0074 \\
\hline 25 & WINCHESTER & $\mathrm{A}$ & -0.0071 \\
\hline 26 & FRANKLIN & A & -0.0508 \\
\hline 27 & SUSSEX & A & -0.0763 \\
\hline 28 & MANASSAS & A & -0.0812 \\
\hline 29 & WILLIAMSBURG & A & -0.1001 \\
\hline 30 & GOOCHLAND & A & -0.1112 \\
\hline
\end{tabular}

gangland (organized crime involvement) vector. There were no significant relationships to report from this comparison.

Table 9 gives the top 30 jurisdictions of Virginia with respect to the gangland (organized crime involvement) likelihood index and also shows how the jurisdictions are clustered. Given the 121 Virginia jurisdictions being considered, of the top 30 with respect to the likelihood index, thirteen are clustered together. Only one other jurisdiction from cluster $\mathrm{B}$ appears outside the top 30; this one jurisdiction is Fairfax County PD (31). Each of the other crime parameters related to the victim and the offender was compared to the juvenile gang vector. There were no significant relationships to report from this comparison.

Table 10 gives the top 30 jurisdictions of Virginia with respect to the juvenile gang likelihood index and also shows how the jurisdictions are clustered. Given the 121 Virginia jurisdictions being considered, of the top 30 with respect to
TABLE 10: Likelihood index and clustering for juvenile gang.

\begin{tabular}{|c|c|c|c|}
\hline & Name & Cluster & $\begin{array}{c}\text { Juvenile gang } \\
\text { likelihood index }\end{array}$ \\
\hline 1 & NORFOLK & B & 0.8424 \\
\hline 2 & ROANOKE & B & 0.8387 \\
\hline 3 & RICHMOND & B & 0.7987 \\
\hline 4 & PORTSMOUTH & B & 0.7977 \\
\hline 5 & GREENSVILLE & B & 0.7575 \\
\hline 6 & CHESAPEAKE & B & 0.7211 \\
\hline 7 & NEWPORT NEWS & B & 0.7112 \\
\hline 8 & WILLIAMSBURG & B & 0.6639 \\
\hline 9 & WYTHE & B & 0.5719 \\
\hline 10 & ALEXANDRIA & B & 0.5597 \\
\hline 11 & LYNCHBURG & B & 0.5452 \\
\hline 12 & MARTINSVILLE & B & 0.5355 \\
\hline 13 & PULASKI & B & 0.4884 \\
\hline 14 & HAMPTON & B & 0.4848 \\
\hline 15 & SPOTSYLVANIA & B & 0.451 \\
\hline 16 & POWHATAN & B & 0.442 \\
\hline 17 & PETERSBURG & A & 0.4207 \\
\hline 18 & CHARLOTTESVILLE & $\mathrm{A}$ & 0.4064 \\
\hline 19 & HOPEWELL & A & 0.3519 \\
\hline 20 & RICHMOND & A & 0.208 \\
\hline 21 & GALAX & A & 0.2025 \\
\hline 22 & BRISTOL & A & 0.2012 \\
\hline 23 & SUFFOLK & A & 0.1925 \\
\hline 24 & CAROLINE & $\mathrm{A}$ & 0.121 \\
\hline 25 & CLARKE & A & 0.0939 \\
\hline 26 & WINCHESTER & $\mathrm{A}$ & 0.0893 \\
\hline 27 & DANVILLE & A & 0.0834 \\
\hline 28 & SUSSEX & A & 0.051 \\
\hline 29 & CAMPBELL & A & 0.0119 \\
\hline 30 & FRANKLIN & A & -0.0773 \\
\hline
\end{tabular}

the likelihood index, sixteen are clustered together. No other jurisdiction from Cluster B appears outside the top 30 .

\section{Conclusion}

The NIBRS provides a wealth of incident level data for use in analysis. The methods investigated in this research yielded promising preliminary results. The methods were applied only to the assault data from 2005 but can easily be extended to other crime types and to other years to validate these results and also provide longitudinal investigation.

The comparison between the crime type vector and the individual parameters vectors helped in two cases (hate crimes and drug dealing) to determine which factors was more related to those crimes. The different types of analyses that were conducted on the jurisdictions helped to validate one another. The likelihood index looked at whether a certain crime pattern existed in that jurisdiction, while the clustering 
method sought to cluster all the jurisdictions based on the crime patterns of that jurisdiction. This information could be useful to assist law enforcement agencies or policy makers in determining which jurisdictions share common challenges that could possibly be addressed through cooperation and sharing resources between jurisdictions.

The next steps would be to utilize this same approach for data from other states or perhaps a larger region to examine if the same information is observed from the analyses. It will be interesting to see if Virginia data and other states have the same patterns or if different patterns emerge. Further research and refinement of these methods should yield tools that would provide researchers, law enforcement agencies, and government officials with a means to find patterns of different crime types and possibly identify jurisdictions that may be likely to experience that type of crime.

\section{Conflict of Interests}

Peixin Zhao, Marjorie Darrah, Jim Nolan, and Cun-Quan Zhang certify that there is no actual or potential conflict of interests in relation to this paper.

\section{Acknowledgments}

First author was partially supported by the China Postdoctoral Science Foundation Funded Project (2011M501149), the Humanity and Social Science Foundation of Ministry of Education of China (12YJCZH303), the Special Fund Project for Postdoctoral Innovation of Shandong Province (201103061), the Informationization Research Project of Shandong Province (2013EI153), the National Statistical Science Project (2013LZ38), and Independent Innovation Foundation of Shandong University (IIFSDU) (IFW12109).

\section{References}

[1] Y. Akiyama and J. Nolan, "Methods for understanding and analyzing NIBRS data," Journal of Quantitative Criminology, vol. 15 , no. 2, pp. 225-238, 1999.

[2] C. Dunn and T. Zelenock, "NIBRS data available for secondary anlaysis," Journal of Quantitative Criminology, vol. 15, no. 2, pp. 239-248, 1999.

[3] M. P. Thompson, L. E. Saltzman, and D. Bibel, "Applying NIBRS data to the study of intimate partner violence: Massachusetts as a case study," Journal of Quantitative Criminology, vol. 15, no. 2, pp. 163-180, 1999.

[4] H. N. Snyder, "The Overpresentation of juvenile crime proportions in robbery clearance statistics," Journal of Quantitative Criminology, vol. 13, no. 2, pp. 151-161, 1999.

[5] L. A. Addington and C. M. Rennison, "Rape co-occurrence: do additional crimes affect victim reporting and police clearance of rape?" Journal of Quantitative Criminology, vol. 24, no. 2, pp. 205-226, 2008.

[6] H. Chen, W. Chung, J. J. Xu, G. Wang, Y. Qin, and M. Chau, "Crime data mining: a general framework and some examples," Computer, vol. 37, no. 4, pp. 50-56, 2004.

[7] O. Maimon and L. Rokach, "Data mining and knowledge discovery handbook," New York, NY, USA, Springer.
National Incident-Based Reporting System, National Archive of Criminal Justice Data, 2005, http://www.icpsr.umich.edu/ NACJD/NIBRS/.

[8] E. Abdu, Clustering categorical data using data summaries and spectral techniques [Ph.D. thesis], The City University of New York, 2009.

[9] Z. Huang, "Extensions to the k-means algorithm for clustering large data sets with categorical values," Data Mining and Knowledge Discovery, vol. 2, no. 3, pp. 283-304, 1998.

[10] D. Gibson, J. Kleinberg, and P. Raghavan, "Clustering categorical data: an approach based on dynamical systems," in Proceedings of the 24th InternationalConference on Very Large Databases, 1998.

[11] V. Ganti, J. Gehrke, and R. Ramakrishnan, "CACTUS clustering categorical data using summaries," in proceedings of the 5th ACM SIGKDD International Conference on Knowledge Discovery and data mining, pp. 73-83, 1999.

[12] S. Guha, R. Rastogi, and K. Shim, "ROCK: a robust clustering algorithm for categorical attributes," in Proceedings of the 15th International Conference on Data Engineering (ICDE '99), pp. 512-521, March 1999.

[13] D. Barbará, J. Couto, and Y. Li, "COOLCAT: an entropybased algorithm for categorical clustering," in Proceedings of the 11th International Conference on Information and Knowledge Management (CIKM '02), pp. 582-589, November 2002.

[14] P. Andritsos, Scalable clustering of categorical data and applications [Ph.D. thesis], University of Toronto, 2004.

[15] M. Zaki, M. Peters, I. Assent, and T. Seidl, "Clicks: an effective algorithm for mining subspace clusters in categorical datasets," Data and Knowledge Engineering, vol. 60, no. 1, pp. 51-70, 2007.

[16] Y. Ou and C. Q. Zhang, "A new multimembership clustering method," Journal of Industrial and Management Optimization, vol. 3, no. 4, pp. 619-624, 2007.

[17] R. N. Shepard and P. Arabie, "Additive clustering: representation of similarities as combinations of discrete overlapping properties," Psychological Review, vol. 86, no. 2, pp. 87-123, 1979.

[18] A. V. Lukashin and R. Fuchs, "Analysis of temporal gene expression profiles: clustering by simulated annealing and determining the optimal number of clusters," Bioinformatics, vol. 17, no. 5, pp. 405-414, 2001.

[19] Y. Xu, V. Olman, and D. Xu, "Clustering gene expression data using a graph-theoretic approach: an application of minimum spanning trees," Bioinformatics, vol. 18, no. 4, pp. 536-545, 2002.

[20] P. Zhao and C. Q. Zhang, "A new clustering method and its application in social networks," Pattern Recognition Letters, vol. 32, no. 15, pp. 2109-2118, 2011. 

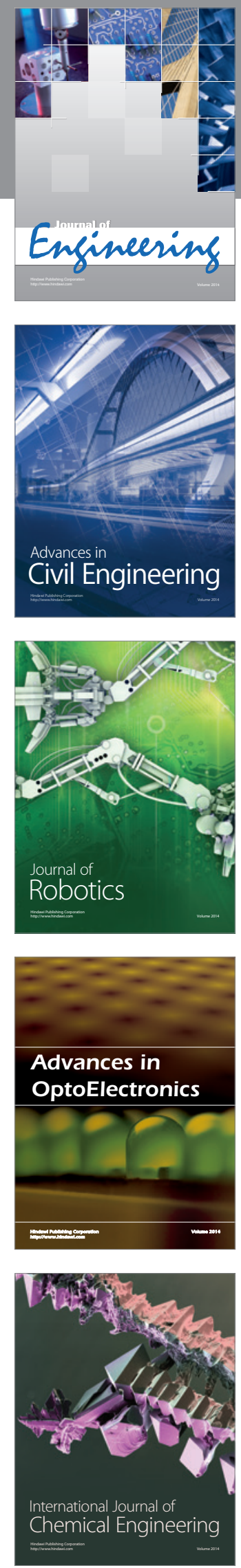

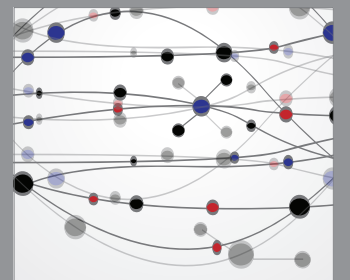

The Scientific World Journal
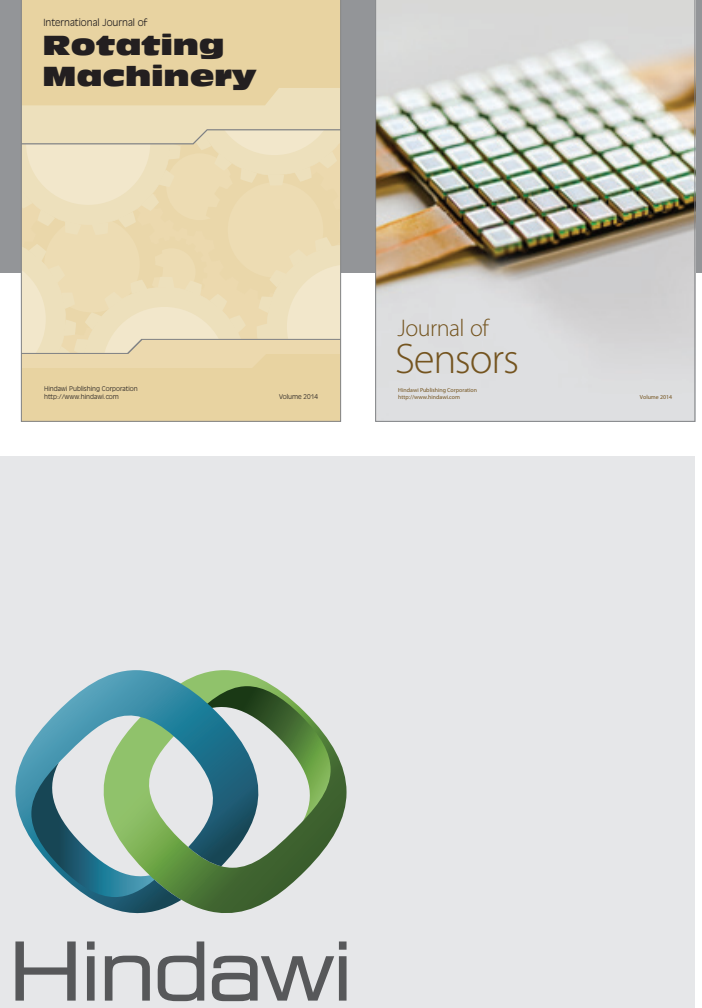

Submit your manuscripts at http://www.hindawi.com
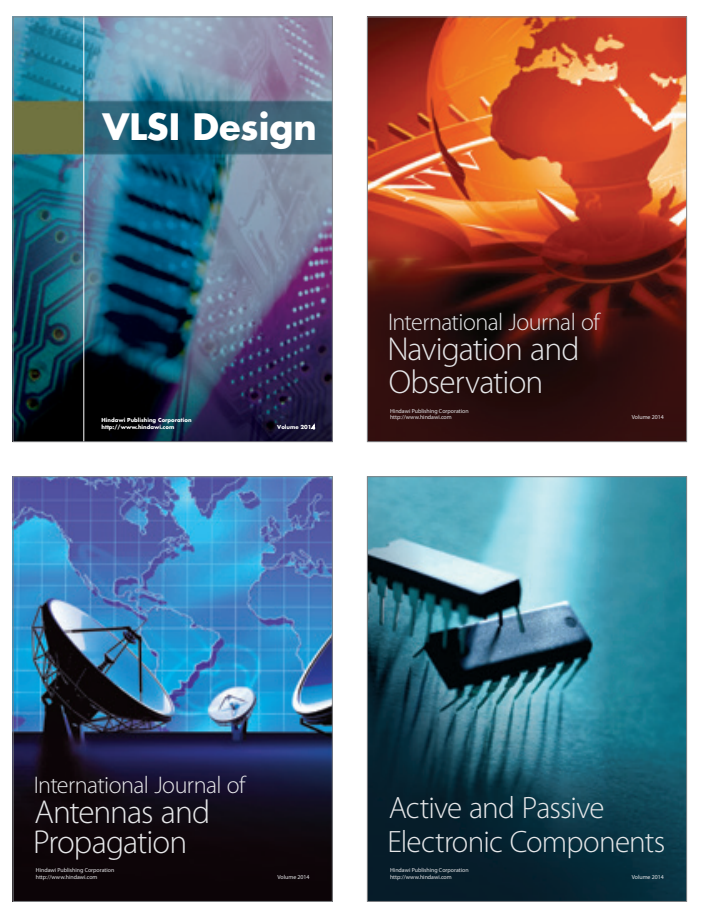
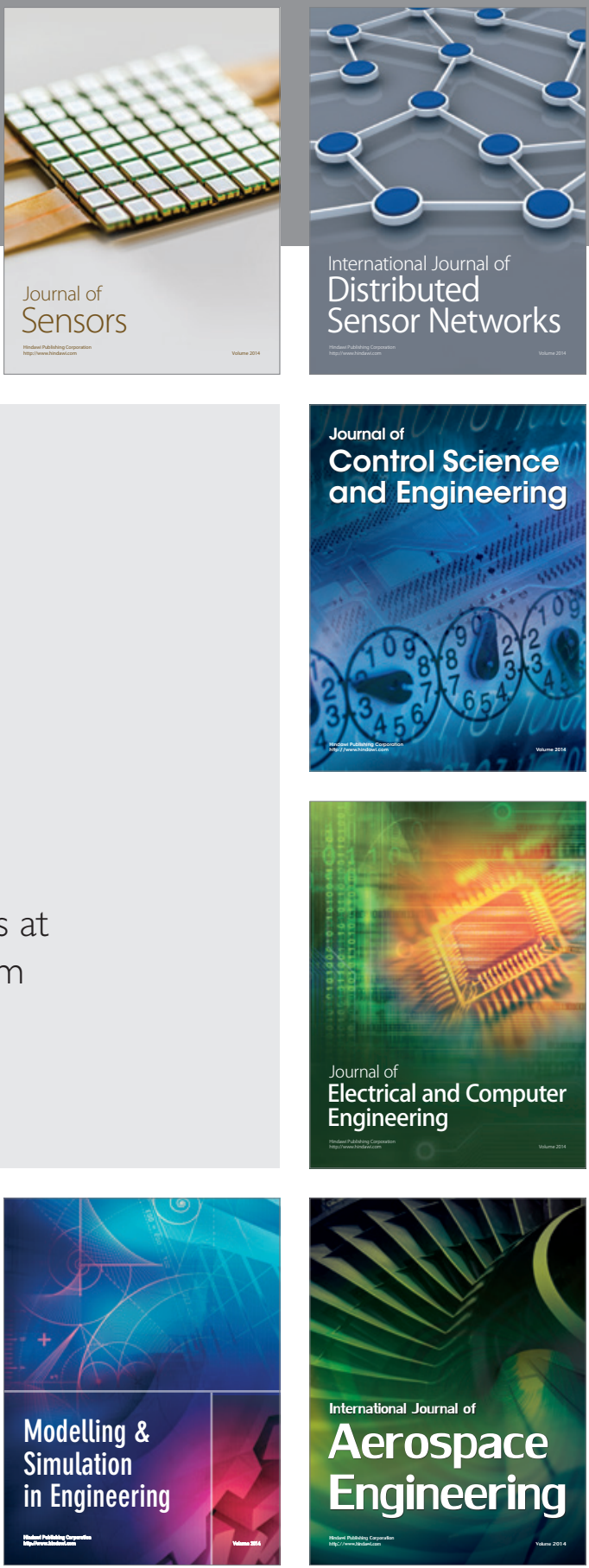

Journal of

Control Science

and Engineering
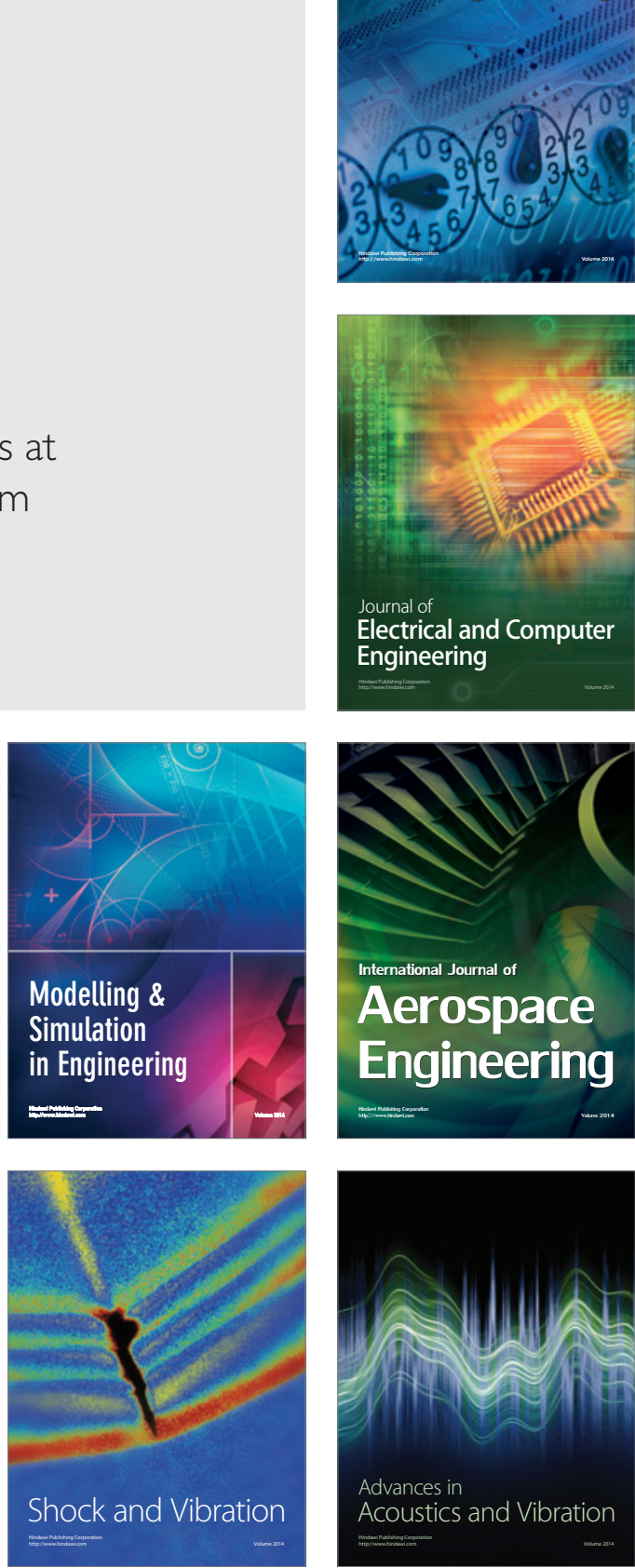